\title{
Phagocytosis induces superoxide formation and apoptosis in macrophages
}

\author{
Jae-Bong Park \\ Department of Biochemistry \\ College of Medicine \\ Hallym University \\ Ockchon 1, Kangwon-do 200-702, Korea \\ Tel, 82-33-248-2542; Fax, 82-33-244-8425; \\ E-mail, jbpark@hallym.ac.kr
}

Accepted 25 August 2003

Abbreviations: FcR, Fc receptor; CR, complement receptor; fMLP formyl-methionyl-leucyl-phenylalanine; GAP, GTPase-activating protein; GEF, guanine nucleotide exchange factor; GM-CSF, granulocyte macrophage colony-stimulating factor; GXM, glucuronoxylmannan; IOZ, IgG-opsonized zymosan; COZ, complementopsonized zymosan; IFN- $\gamma$, interferon- $\gamma$, IgG, imunoglobulin $G$; ITAMs, immunoglobulin gene family tyrosine activation motifs; JNK, c-jun N-terminal kinase; LIMK, LIM kinase; LPS, lipopolysaccharide; MLCK, myosin light chain kinase; NO, nitric oxide; NSF, $\mathrm{N}$-ethylmaleimide-sensitive factor; OPMN, PMN in the oral cavity; $\mathrm{PAF}$, platelet activating factor; $\mathrm{PH}$, pleckstrin homology; PMA, phorbol 12-myristate 13-acetate; PKC, protein kinase C; PAK, p21-activated kinase; PI3K, phosphatidylinositol-3 kinase; PIP3, phosphatidylinositol-3,4,5-triphosphate; PLD, phospholipase D; PMN, polymorphonuclear leukocytes; PS, phosphatidylserine; SHIP, src homology 2 domain-containing inositol 5'-phosphatase; RhoGDI, Rho GDP dissociation inhibitor; ROK, Rho-dependent protein kinase; ROS, reactive oxygen species, TNFR, tumor necrosis factor receptor; SAPK, stress activating protein kinase; $\mathrm{SH} 2$, Src homology 2; SNARE, soluble NSF attachment protein receptor; TNF- $\alpha$, tumor necorsis factor- $\alpha$; VAMP, Vesicle-associated membrane protein; WASP, Wiskott-Aldrich syndrome protein

\footnotetext{
Abstract

Phagocytosis by inflammatory cells is an essential step and a part of innate immunity for protection against foreign pathogens, microorganism or dead cells. Phagocytosis, endocytotic events sequel to binding particle ligands to the specific receptors on phagocyte cell surface such as Fc $\gamma$ recptor $(F c \gamma R)$, complement receptor (CR), $\beta$-glucan receptor, and phosphatidylserine (PS) receptor, require actin assembly, pseudopod extension and phagosome closure. Rho GTPases (RhoA, Cdc42, and $\operatorname{Rac} 1)$ are critically involved in these processes. Abrupt superoxide formation, called as oxi-
}

dative burst, occurs through NADPH oxidase complex in leukocytes following phagocytosis. NADPH oxidase complex is composed of membrane proteins, $\mathrm{p}^{22^{\mathrm{PHOX}}}$ and $\mathrm{gp} 91^{\mathrm{PHOX}}$ and cytosolic proteins, $\mathrm{p} 40^{\mathrm{PHOX}}, \mathrm{p} 47^{\mathrm{PHOX}}$ and $\mathrm{p} 67^{\mathrm{PHOX}}$. The cytosolic subunits and Rac-GTP are translocated to the membrane, forming complete NADPH oxidase complex with membrane part subunits. Binding of imunoglobulin G (IgG)- and complement-opsonized particles to $F C \gamma R$ and $C R$ of leukocytes induces apoptosis of the cells, which may be due to oxidative burst and accompanying cytochrome $c$ release and casapase-3 activation.

Keywords: apoptosis; NADPH oxidase; phagocytosis; Rho GTPases; superoxide

\section{Introduction}

In this review, a series of phagocytosis, superoxide formation and apoptosis of phagocyte cells will be discussed. The phagocytosis is regulated by a variety of participants including receptors, protein kinases, effector proteins, cytoskeletal rearrangement and Rho GTPases. Especially, NADPH oxidase is a key enzyme in oxidative respiratory burst, which follow the phagocytosis. Excessive superoxide could induce apoptosis of phagocytes themselves. Each step is controlled by various regulators.

\section{Phagocytosis in macrophages}

Phagocytosis is an essential mechanism that inflammatory leukocytes utilize in engulfing and killing or clearing pathogenic microorganisms or dead cells. It is well established that invading pathogens were initially neutralized by battery of circulating host defensive proteins and quickly cleared from circulation or body fluid by inflammatory leukocytes via phagocytosis. The recognition and engulfing of pathogen complex is triggered by interaction with specific receptors on the leukocytes, and followed by cellular actin assembly, pseudopod extension and phagosome closure (Aderem and Underhill, 1999). Rho family GTPase proteins known to be involved in many physiological functions like rearrangement of cytoskeletons, regulation of cellular morphology, chemotaxis, and regulation of transcription (Hall, 1998), are essential in actin dynamics 
necessary for phagocytosis and engulfment (Chimini and Chavrier, 2000). Ligands interaction with Fc $\gamma$ receptors (FcyRs) and complement receptors (CRs) that are linked to distinct signaling pathways, induce both morphologically and mechanistically distinct phagocytic processes.

\section{FcyR-mediated phagocytes}

FcyR can recognize $F c$ domain of immunoglobulin $G$ $(\lg G)$. FcyRs that mediate phagocytosis in human macrophages include FcyRI, IIA, and FcyRIII (Ravetch, 1997). The human FcyRIIA is a monomeric protein which has an extracellular Fc binding domain, a transmembrane domain, and a cytoplasmic tail domain containing two immunoglobulin gene family tyrosine activation motifs (ITAMs), which is phosphorylated by tyrosine kinase of the Src family activated upon FcyR aggregation. FcyRI and FcyllA have also extracellular Fc binding domains similar to FcyRIIA, but lack ITAMs on their cytoplasmic tails. For proper signaling, these receptors must interact with a dimmer of or $\gamma$ subunit, which is small transmembrane proteins that contain the ITAMs needed for signal transduction (Aderem and Underhill, 1999). Other protein tyrosine kinase, Syk, is then recruited through Src homology 2 (SH2) domains to the phosphorylated ITAMs, and undergoes autophosphorylation and activation (Chimini and Chavrier, 2000). The activation of Syk kinase triggers many pathways leading to transcriptional activation, cytoskeletal rearrangement, and the release of inflammatory mediators (Andrem and Underhill, 1999).

It was found that $\mathrm{Cdc} 42 / \mathrm{Rac}$ regulated the phagocytosis mediated through $\mathrm{FcyR}$ in macrophages (Cox et al., 1997; Caron and Hall, 1998; Massol et al., 1998). The expression of dominant negative inhibitory mutant forms of $\mathrm{Cdc} 42$ and Rac1 in phagocytic cells inhibits particle uptake into phagocytes. Rac1 inhibition prevented pseudopod fusion and phagosome closure. In addition, in response to ligation of FcyRs for IgG, the guanine nucleotide exchange factor (GEF) Vav translocates to nascent phagosomes and catalyzes GTP loading on Rac, but not Cdc42. The Vavinduced Rac activation proceeds independently of Cdc42 function, suggesting distinct roles for each GTPases during engulfment (Patel et al., 2002). On the other hand, Vav is stimulated by both tyrosine phosphorylation and phosphoinositide product of the $\mathrm{PI} \mathrm{K}$ that binds to the pleckstrin/homology $(\mathrm{PH})$ domain (Crespo et al., 1997) (Figure 1).

\section{Complement receptor-mediated phagocytosis}

Another receptor through which phagocytosis occurs is the CRs, which recognize the $\mathrm{C} 3 \mathrm{~b} / \mathrm{C} 3 \mathrm{bi}$ fragments. The complement fragments are generated by cleavage of $\mathrm{C} 3$ to active $\mathrm{C} 3 \mathrm{~b}$ and subsequently to inactive
C3b (C3bi). CR1 is thought to participate mainly in particle binding. CR3 (CD11b/ CD18; Mac-1) and CR4 (CD11C/CD18) are heterodimers of integrin members, $\alpha_{m} \beta_{2}$ and $\alpha x \beta_{2}$, respectively, which are responsible for particle internalization (Aderem and Underhill, 1999).

Rho appeared to be involved in the regulation of phagocytosis that is mediated through CR3 (Caron and Hall, 1998). The inhibition of RhoA induced by C3 exoenzyme results in the block of CR3-mediated particle uptake. On the contrary, C3 exoenzyme does not inhibit the uptake of $\lg G$-opsonized particles and expression of dominant negative forms of $\mathrm{Cdc4} 2$ and Rac1 does not affect CR3-mediated phagocytosis (Caron and Hall, 1998). However, Rho appeared to be also involved in FcyR-mediated phagocytosis; the inactivation of Rho by $\mathrm{C} 3$ exoenzyme resulted in the complete abrogation of FcyR-mediated phagocytosis (Hackam et al., 1997). In addition, FcyR-mediated phagocytosis is abrogated by $\mathrm{C} 3$ exoenzyme in COS cells, which become phagocytic upon transfection of the FcyRIIA receptor (Hackam et al., 1997). The clustering of receptors in response to opsonin, an essential step in Fcy-induced signaling, is the earliest event to be inhibited by C3 exoenzyme (Hackam et al., 1997). Taken together, Rho is also required for the initiation of phagocytosis by $\mathrm{Fc \gamma Rs}$ in macrophages. The reason of discrepancy between Rhoinvolvement in FcyR- and CR-mediated phagocytosis is presently unclear, although question was raised in regards to the difference of initial binding of IgGcoated particles (Caron and Hall, 1998) (Figure 1).

The precise mechanism of RhoA of how it regulates the formation of actin rich forci during CR3mediated phagocytosis remains yet to be resolved.

Another small GTPase, constitutively active Rap1 is sufficient for functional activation of CR3 allowing phagocytosis of C3bi-opsonized target, and inhibition of Rap1 abolishes activation of CR3 induced by phobol esters, lipopolysaccharide (LPS), tumor necrosis factor (TNF)- $\alpha$ or platelet activating factor (PAF). Rap1 may link the signaling through $F c \gamma R$ and that through CR3. IgG-coated particles induce a rapid and transient Rap1 activation. However, Rap1 is activated independently of respiratory burst induction (M'Rabet, 1998). In turn, Rap1 activation specifically controls the binding properties of CR3 towards its physiological ligand, the complement-opsonized phagocytic target (Caron et al., 2000).

CR3 requires additional stimuli such as phorbol 12-myristate 13-acetate (PMA), chemokines, TNF- $\alpha$ or adhesion to fibronectin-coated surface, which results in activation of protein kinase $C$ (PKC) and increased expression of CR3 at the surface (Chimini and Chavrier, 2000). In some case, CR3 and CR4 are also involved in antibody-mediated complement-independent phagocytosis (Taborda and Casadevall, 2002). 
$\lg \mathrm{M}$ and $\lg \mathrm{A}$-mediated phagocytosis of $C$. neoformans is dependent on CR3 expression, and is inhibited by soluble glucuronoxylmannan (GXM), which binds CD18. Since CD18 can bind GXM, it is considered that $\lg \mathrm{M}$ - and $\lg \mathrm{A}$-mediated phagocytosis reflected facilitated binding of exposed capsular polysaccharide by CR3 and CR4 as a consequence of antibody binding to capsule of microorganism (Taborda and Casadevall, 2002).

\section{Mannose receptor-mediated phagocytosis}

The third type of receptor involved in phagocytosis is the mannose receptor that recognizes mannose and fucose saccharides in the capsule on the lipopolysaccharide of invading bacteria (Brown, 1995). Cellular recognition of nonopsonized zymosan is mediated by mannose and $\beta$-glucan receptors (Giaimis et al., 1993). Nonopsonized zymosan can be also ingested through CR3 (Le Cabec et al., 2000), the lectin domain of which binds to soluble $\beta$-glucan and mediates phagocytosis of particles containing $\beta$-glucan, such as zymosan (Ross et al., 1985). Thereby, it is proposed that CR3 be $\beta$-glucan receptor (Ross, 2000). However, it was recently reported that dectin-1 is a major $\beta$-glucan receptor on macrophages (Brown et al., 2002).

\section{Cytoskeleton rearrangements during phagocytosis}

Localized actin polymerization provides the driving force for engulfment of particles. A variety of signals can converge to locally reorganize the actin cytoskeleton at a phagosome (May and Machesky, 2001). Celluar content of F-actin increases transiently during phagocytosis. Immunofluorescence localization of myosins in macrophages fixed at various times during FcyR-mediated phagocytosis indicates that myosin II and $\mathrm{IXb}$ are concentrated in early phagosomes, myosin IC increased later, and myosin $V$ appeared after phagosome closure (Diakonova et al., 2002). The morphology of internalization and the molecular pathways involved in both FcyR- and CR-mediated phagocytosis differ between the two receptors (Allen and Aderem, 1996). During ingestion of complement-opsonized zymosan (COZ), the particles sink into the cells, punctuate structures rich in F-actin, vinculin, $\alpha$-actinin, paxillin and phosphotyrosin-containing proteins are distributed over the phagosome surface. Moreover, CR-mediated internalization requires intact microtubules and is accompanied by the accumulation of vesicles beneath the forming phagosome, suggesting membrane trafficking plays a key role in CRmediated phagocytosis (Allen and Aderem, 1996). By contrast, during FcyR-mediated phagocytosis, all proteins examined are uniformly distributed on or near phagosome surface. Local polymerization of actin fila- ments supports the protrusion of pseudopodia that eventually engulf the particles upon engagement of FcyRs in macrophages. Cdc42 and Rac1 control actin filament assembly through proteins of the WiskotAldrich Syndrome protein (WASP) that interact with Arp2/3 (Machesky and Insall, 1998). Arp2/3 complex, a multifunctional actin organizer, is involved in actin remodeling during phagocytosis. This complex is required for both FcyR- and CR3-mediated phagocytosis, although the upstream signals that recruit the Arp2/3 complex to phagosomes differ for the two receptors (May et al., 2000). In addition, N-WASP accumulates at the nascent phagosome (May et al., 2000), indicating that WASP is an important effector protein that link $\mathrm{Cdc} 42$ and $\mathrm{Rac}$ to cytoskeleton regulation during phagocytosis. p21-activated kinase (PAK-1) is also localized to the phagosome, and the activity of PAK-1 is controlled by Cdc42/Rac and has been shown to regulate actinomyosin cytoskeleton contractility (Sanders et al., 1999).

On the other hand, LIM kinase-1 (LIMK1) regulates the macrophage-like U937 cells through phosphorylation of cofilin and enhances the formation of filamentous actin. This results lead to the increase of phagocytosis, superoxide production, and translocation of LIMK1 to plasma membrane, when the cells are activated with opsonized zymosan particles (Matsui et al., 2002).

\section{Membrane mobilization during phagocytosis}

Lipid product of phosphatidylinositol-3 kinase (PI3K), phosphatidylinositol-3,4,5-triphophate (PIP3) is required for pseudopod extension and phagosome closure. PIP3 is rapidly accumulated in phagocytic cups after ligation of FcyRs in macrophages (Cox et al., 1999; Marshall et al., 2001). Moreover, inhibition of PI3K activity blocks pseudopod extension and phgocytosis without affecting actin polymerization (Cox et al., 1999). Moreover, over-expression of Src homology 2 domain-containing inositol 5'-phosphatase (SHIP) in macrophages led to an inhibition of phagocytosis mediated by FcyR and CR3. SHIP is localized to FcyRand CR3-containing phagocytic cups and was recruited to the cytoskeleton upon clustering of CR3. PI3K and SHIP regulate multiple forms of phagocytosis and endogenous SHIP plays a role in modulating $\beta 2$ integrin outside-in signaling (Cox et al., 2001). However, it is not clear whether SHIP is essential for regulation of membrane mobilization.

Myosin $X$ is also recruited to the forming phagosome through the interaction of its $\mathrm{PH}$ domains with membrane PIP3. The motor head domain of Myosin $X$ interacts with actin filament and moves towards the tip of filaments with growing pseudopod. Consequently, by this dual interaction, Myosin $X$ would be 
able to couple actin polymerization and pseudopod extension (Chavrier, 2002; Cox et al., 2002).

The internalization of the surface during phagocytosis is predicted to reduce the surface area of the phagocytes. Contrary to this prediction, phagocytosis is associated exocytosis, which requires soluble $\mathrm{N}$ ethylmaleimide sensitive factor (NSF) attachment protein receptor (SNARE) proteins and ATPase NSF (Hackman et al., 1998). In addition, membranes required for pseudopod extension are also provided by insertion of recycling endosome membranes enriched in the SNARE VAMP3 at the site of phagocytosis (Bajno et al., 2000). ARF6, one of Ras-related GTPase, is required in $\mathrm{Fc \gamma}$ receptor-mediated phagocytosis in macrophages (Zhang et al., 1998).

\section{Phagocytosis of apoptotic cells}

Phagocytosis of cells dying by apoptosis differs in many ways from the phagocytic events of IgG-and CR-mediated phagocytosis. One of its peculiarities is the active silencing of the inflammatory responses that are normally the sequel to phagocyte activation. The interaction between the apoptotic cell surface and phagocytotic receptor is rather unclear, and the molecular dissection of the process is still limited (Chimini and Chavrier, 2000). Abnormal exposure of phospha- tidylserine (PS) on the outermonolayer has been reported as an essential determinant for recognition by phagocytes. Recently, stereospecific PS receptor has been identified, although the molecular details of its action are still to be answered (Fadok et al., 2000). Integrin receptors are important for the phagocytosis of apoptotic cells. It was documented that integrin $\alpha v \beta 5$ receptor mediates both binding and internalization of apoptotic cells. Internalization is dependent upon signaling through $\beta 5$ cytoplasmic tail, and engagement of the $\alpha v \beta 5$ heterodimer results in recruitment of the p130cas-Crkll-Dock180 molecular complex, which in turn triggers Rac1 activation and phagosome formation (Albert et al., 2000).

\section{Superoxide formation through NADPH oxidase}

\section{NADPH oxidase complex}

Subsequent to phagocytosis in macrophage, there is an abrupt increase of superoxide formation known as the oxidative burst, which is catalyzed by an NADPH oxidase enzyme complex. The NADPH oxidase is a membrane-associated enzyme complex that generates superoxide $\left(\mathrm{O}_{2}^{-}\right)$by the one-electron reduction of oxygen, using NADPH as the electron donor (Babior,
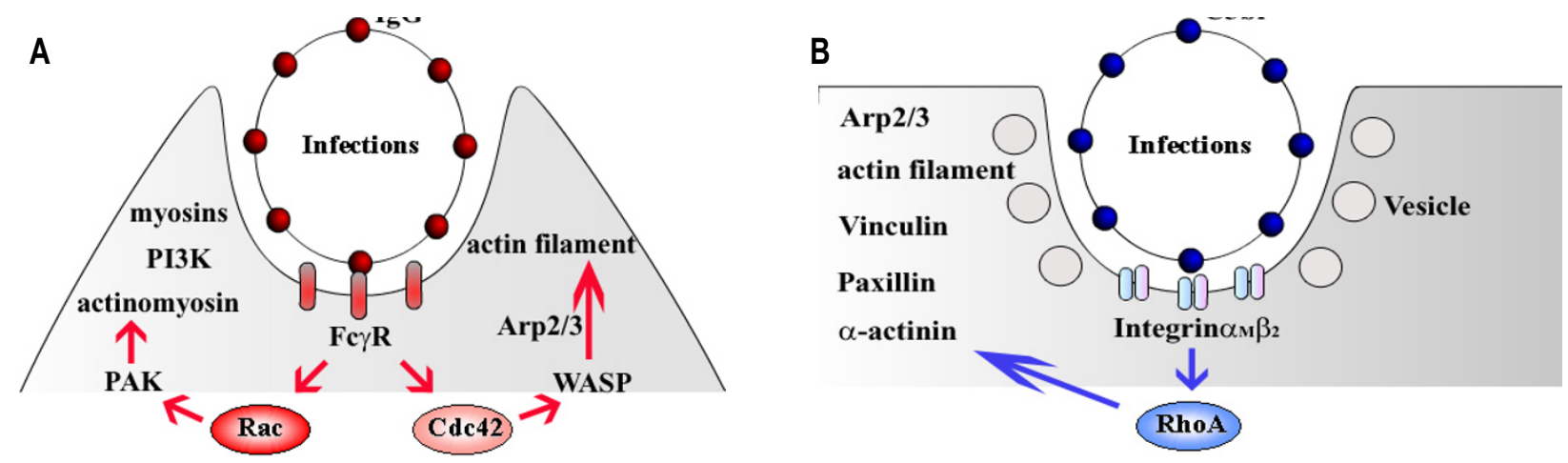

Figure 1. A model for FcR- and CR3-mediated phagocytosis. (A) FCR-mediated phagocytosis. IgG coated on the particle including pathogens binds to $F c \gamma R$ at the surface of the macrophage and triggers FcyR aggregation, and tyrosine kinase is activated and phosphorylates the FcyR. Other protein tyrosine kinase, Syk, is recruited at the phosphorylated site, and undergoes autophosphorylation and activation. Cdc42 activation by a guanine-nucleotide exchange factor (GEF) leads to the recruitment of WASP. In turn, WASP activates the Arp2/3 complex that induces actin polymerization to produce the protrusive force for pseudopod extension. Activation of a Rac1 GEF, possibly Vav, which is translocated to phagosome and stimulated by both tyrosine phosphorylation and phosphoinositide product of PI3K, catalyzes GDP/GTP exchange on Rac1. GTP-Rac1 interacts with and activates the Pak1, which may trigger the actinomyosin contractility involved in phagosome closure (Chimini and Chavrier, 2000). However, it is not clear how the signal pathway is coupled between FcyR and the activation of Cdc42 and Rac1. PI3K is also involved in pseudopod extension (Cox et al., 1999) and myosin $X$ is able to couple actin polymerization and pseudopod extension (Cox et al., 2002). (B) CR3-mediated phagocytosis. Integrin $\alpha M \beta 2$ (Mac-1, CD11b/CD18) is the complement receptor (CR3), which binds complement $\mathrm{C} 3 \mathrm{bi}$ on the surface of complement-opsonized particles. Binding of integrin $\alpha M \beta 2$ to $\mathrm{CR} 3$ activates RhoA by unknown mechanism, which triggers CR3-mediated phagocytosis. In turn, these may induce integrin $\alpha M \beta 2$ clustering, assembly of actin filaments, and recruitment of cytoskeletal proteins, including vinculin, paxillin and $\alpha$-actinin to generate F-actin-rich foci. RhoA-mediated actin assembly may require the activation of the nucleating activity of the Arp $2 / 3$ complex that is recruited to the F-actin foci. Activated RhoA may promote myosin filament formation and contractility resulting in the particle sinking into the cytosol (Chimini and Chavrier, 2000). Small vesicles are located below phagosomal plasma membrane at which complement opsonized particles are bound to CR3. These vesicles may be fused to the plasma membrane leading to the augmentation of phagosomal plasma membranes and forming phagosomes. 


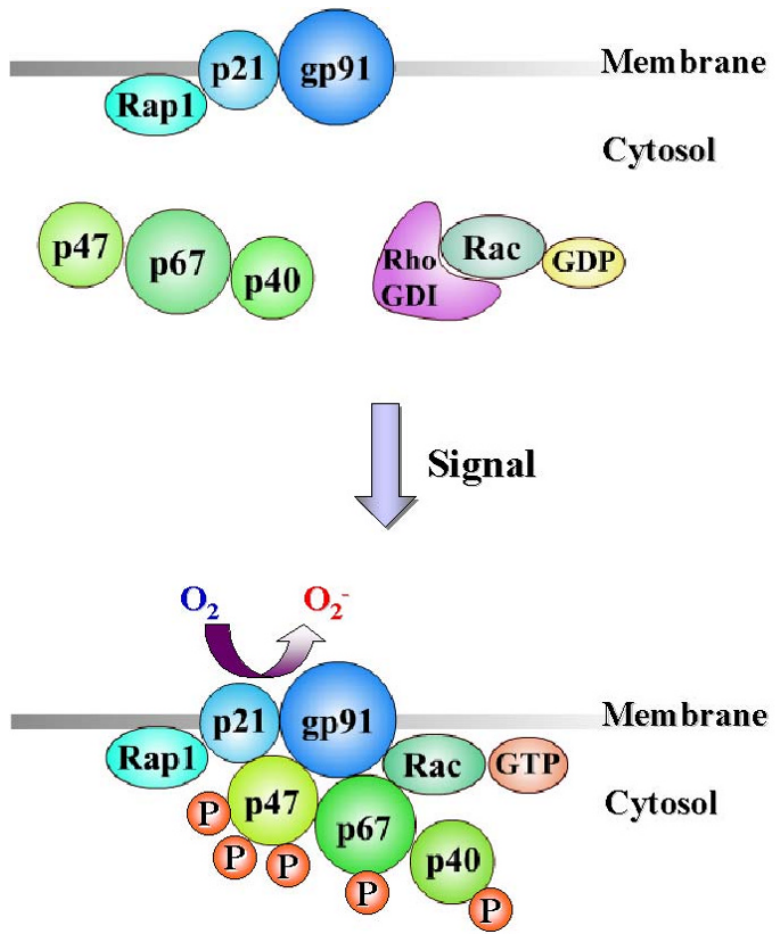

Figure 2. Activation of NADPH oxidase complex. When phagocytes are activated, some signals induce the activation of cytosolic factors $\left(\mathrm{p} 40^{\text {PHOX }}, \mathrm{p} 47^{\mathrm{PHOX}^{\mathrm{HOX}}}\right.$ and $\mathrm{p} 67^{\text {PHOX }}$ ) like phosphorylation of $\mathrm{p} 47^{\mathrm{PHOX}^{\mathrm{POX}} \text {, and }}$ p $67^{\text {PHOX }}$ and GTP-binding to Rac, and translocation of cytosolic factors to membrane fractions to form a complex of NADPH oxidase with

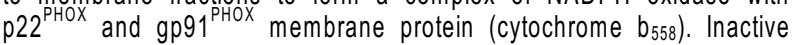
GDP-bound Rac exists in complex form with Rho GDP dissociation inhibitor (RhoGDI), and the complex is broken to the active GTP. bound Rac that translocates to NADPH oxidase complex when the cells are stimulated.

1999). NADPH oxidase is composed of multiple subunits from membrane and cytosolic fractions. The core enzyme of NADPH oxidase is composed of five components. Among them, $\mathrm{p} 22^{\text {PHOX }}$ and $\mathrm{gp} 91^{\text {PHOX }}$ exist in the membranes of secretory granular vesicles that fuse with the plasma membrane upon phagocytosis, and $\mathrm{p} 22^{\text {PHOX }}$ and gp91 ${ }^{\text {PHOX }}$ form a heterodimeric flavohemoprotein known as cytochrome $b_{558}$ (Rotrosen et al., 1993). The other components, p40 ${ }^{\text {PHOX }}$, p47 $7^{\text {PHOX }}$, and $\mathrm{p} 67^{\mathrm{PHOX}}$ are located in the cytosol as a complex (Wientjes et al., 1996). When the cells are activated, p4 $7^{\text {PHOX }}$ becomes highly phosphorylated by protein kinases (Park and Babior, 1997), and the entire cytosolic complex of $\mathrm{p} 40^{\mathrm{PHOX}}, \mathrm{p} 47^{\mathrm{PHOX}}$, and $\mathrm{p} 67^{\mathrm{PHOX}}$ translocates to the membrane, where it associates with cytochrome $b_{558}$ to assemble the active NADPH oxidase (Heyworth et al., 1991). In addition to p4

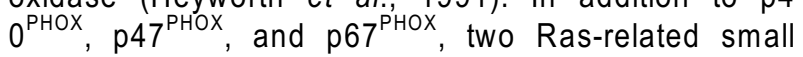
GTP-binding proteins, Rap1 and Rac1 (or Rac2) are required for the activation of NADPH oxidase. Ras-related small GTP-binding proteins, Rac1 (Kreck

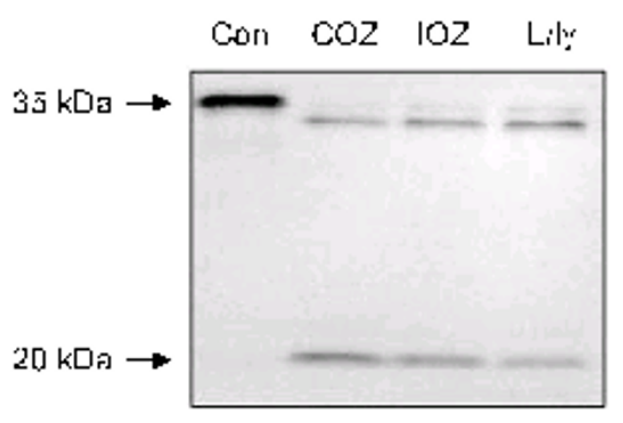

Figure 3. Activation of caspase-3 by lgG-, C3bi-opsonized zymosan particles, and lysopolysaccharide (LPS) and interferon $\gamma$ (IFN $\gamma$ ). Procaspase-3 $(35 \mathrm{kDa})$ was cleaved to active caspase- $3(20 \mathrm{kDa})$ by the stimulation with $\mathrm{IgG}-(\mathrm{IOZ})$, C3bi-opsonized zymosan (COZ) particles, and $1 \mu \mathrm{g} / \mathrm{ml}$ lysopolysaccharide (LPS) plus interferon- $\gamma$ (IFN- $\gamma$ ) in macrophage J774A.1 cells. Phagocytosis of $\mathrm{OZZ}$ and $\mathrm{COZ}$ particles induce ROS formation, which in turn lead to apoptosis of $J 774$ macrophage cells through activation of caspase-3 and release of cytochrome c (Kim et al., 2003).

et al., 1994) and Rac2 (Mizuno et al., 1992) are essential regulators of the activation of NADPH oxidase. Rac2 is the major homologue found in human phagocytes, while Rac1 is the major form in mouse (Kim and Dinauer, 2001). In the resting state of phagocytosis, Rac is localized in the cytoplasm in a dimeric complex with Rho GDP dissociation inhibitor (GDI), while GTP-bound Rac translocates to the membrane independently of $\mathrm{p} 40^{\mathrm{PHOX}}, \mathrm{p} 47^{\mathrm{PHOX}}$, and $\mathrm{p} 67^{\mathrm{PHOX}}$ cytosolic complex translocation during activation of the phagocyte (Bokoch, 1994). Rap1 physically associated with and co-purifies with cytochrome b558 in the membranes (Quinn et al., 1989). Rap1 is phosphorylated by protein kinase $A$ and the phosphorylated Rap1 is inhibited from binding to cytochrome b558 (Bokoch et al., 1991), suggesting that a kinase(s) may regulate the interaction between cytochrome b558 and Rap1. In addition, IgG-coated particles induce a rapid and transient Rap1 activation. In neutrophil, Rap1 is activated independently of respiratory induction (M'Rabet, 1998). The NADPH oxidase is activated on phagosomes and generates superoxide to aid in the killing of phagocytosed microorganisms. It is important that superoxide is primarily released into phagosomes to prevent damage to surrounding cells (Ridley, 2001).

\section{Regulatory proteins involved in superoxide formation}

The subsequent superoxide formation mainly occurs through FcR activation. However, the stimulation of CR3 by anti-CR3 antibody-coated particles (Serrander et al., 1999), by Staphylococcus particles coated with anti-CD18 antibodies (Lofgren et al., 1999), and by nonopsonized zymosan (Le Cabec et al., 2000) in- 
duces superoxide production. Superoxide production by stimulation of serum-opsonized zymosan (SOZ), is attenuated by p38 MAPK inhibitor, SB203580. SOZ stimulation induces the translocation of $\mathrm{p} 47^{\mathrm{PHOX}}$ and Rac to the plasma membrane, and SB203580 completely blocks the translocation of Rac, but only partially blocks that of $447^{\mathrm{PHOX}}$. PI3K inhibitors, wortmanin and LY294002, blocks not only p38 MAPK activation but also Rac activation. However, SB203580 shows no effect on the PI3K activity. Thus it was proposed that $\mathrm{PI3K} / \mathrm{p} 38 \mathrm{MAPK} / \mathrm{Rac}$ pathway is operative in the activation of NADPH oxidase in neutrophils (Yamamori et al., 2002). While SB203580 and PI3K inhibitor attenuates phagocytosis, GF109203X, PKC inhibitor, facilitated it. However, GF109203X significantly attenuates SOZ-induced superoxide formation. These results suggest that p38 MAPK and PI3K participate in both signaling pathways of phagocytosis and superoxide formation, and PKC participates in the signaling pathway of NADPH oxidase activation alone (Yamamori et al., 2000).

On the other hand, inhibition of ERK1/2 by PD98059, a specific inhibitor of ERK kinase, inhibited fornyl Met/Leu/Pro (fMLP)-induced phosphorylation of $\mathrm{p} 47^{\text {PHOX }}$, but weakly affected PMA-induced $\mathrm{p} 47^{\mathrm{PHOX}}$ phosphorylation. Moreover, SB203580 did not inhibit the phosphorylation of $\mathrm{p} 47^{\text {PHOX }}$ induced either by fMLP or by PMA in human neutrophil (Dewas et al., 2000). This suggests that signal pathways for superoxide formation are different each other depending on kinds of stimulation to the cells.

Rac is involved in FcyR-mediated phagocytosis, and directly in the activation of NADPH oxidase. In addition, RhoA was also reported to be involved in the production of $\mathrm{H}_{2} \mathrm{O}_{2}$ in other cell lines such as Swiss 3T3 fibroblast (Koo et al., 1999) and Rat-2 fibroblast (Lee et al., 2000), when stimulated by TGF and EGF, respectively. RhoA has been known as an activator for Rho-dependent protein kinase (ROK), which phosphorylates myosin light chain kinase (MLCK) (Totsukawa et al., 2000), and myosin binding subunit of myosin phosphatase (Kawano et al., 2000), which results in the formation of stress fibers.

Cytoskeleton reorganization is also linked to superoxide formation: Inhibition of superoxide formation by cytochalasin B suggests a necessary role of the cytoskeleton in the signaling pathway that activates the oxidase (Serrander et al., 1999). ML-7, an inhibitor of MLC kinase, inhibited superoxide formation and phagocytosis in some laboratories (Kimura et al., 1996; Masfield et al., 2000), suggesting that cytoskeleton reorganization is important for the superoxide formation. In addition, the inhibition of superoxide formation by ML-7 may arise from the reduction of the phagocytosis, where ML-7 will likely directly inhibits the machinery to produce superoxide: ML-7 was shown to reduce the phosphorylation and the translocation of $\mathrm{p} 47^{\mathrm{PHOX}}$ to the membranes (Heyworth et al., 1995). It has been shown that $\mathrm{p} 22^{\mathrm{PHOX}}$ can be phosphorylated through phospholipase D (PLD), suggesting that PLD activity is required for superoxide formation (Regier et al., 2000). Involvement of PLD was further evidenced by that the activation of PLD is tightly coupled to the phagocytosis of opsonized zymosan by human macrophages (Kusner et al., 1996) and RhoA is an activator of PLD activity (Malcolm et al., 1994). Interestingly, Rac/RhoGDI complex was disrupted in the presence of various lipids like arachidonic acid, phosphatidylinositol, and phosphatidic acid (PA) which can be produced by PLD (Chuang et al., 1993).

Recently it was demonstrated that RhoA is regulated by Rac through superoxide where the change in cellular redox state appeared to couple to the control of actin cytoskeleton rearrangement by Rho GTPase (Nimnual et al., 2003). Rac-mediated ROS production results in the down-regulation of Rho activity. The pathway linking generation of ROS to downregulation of Rho involves inhibition of the low-molecular weight protein tyrosine phosphatase and then an increase in the tyrosine phosphorylation and activation of its target, p190Rho-GAP (Nimnual et al., 2003). Despite the multiple events associated with superoxide formation, it remains to be studied in detail how NADPH oxidase complex is activated.

\section{Apoptosis of phagocytes by reactive oxygen species (ROS)}

Neutrophil apoptosis is accelerated by at least three different routes. First, engagement of death-inducing receptors such as tumor necrosis factor receptor (TNFR) or Fas, induces apoptosis of neutrophils. Second, stress stimuli of physical and chemical agents lead to neutrophil apoptosis. Last, phagocytosis of IgG- or complement opsonized particles triggers apoptosis of neutrophils (Zhang et al., 2003).

\section{Agents inducing apoptosis}

As for the cell death and apoptosis of phagocytes including macrophages and neutrophils, studies have mainly been focused on conditions that lead to endogenous production of ROS or nitric oxide (NO). The factors to induce apoptosis of macrophages through the induction of ROS include azurin, coppercontaining protein involved in electron transfer during denitrification (Yamada et al., 2002), residual oil fly ash, a pollutant dust (Huang et al., 2003), sulfasalazine, a drug used in inflammatory bowel disease (Salh et al., 2002), chromium (VI), a widely used industrial chemical (Bagchi et al., 2001), gliotoxin, an immuno- 
suppressive agent (Suen et al., 2001), cationic liposome (Aramaki et al., 2001), and silica (Shen et al., 2001).

\section{Apoptosis by endogenous ROS}

ROS endogenously produced inside the cells could induce apoptosis of the cells. Although apoptosis of neutrophils may be mediated by endogeneous oxidative products, the physiological roles of ROS in the apoptosis of neutrophil is unknown (Kasahara et al., 1997). ROS are also necessary for apoptosis in neuron, and NADPH oxidase subunits are shown in neurons. NADPH oxidase inhibitor, diphenyleneiodonium (DPI), and NADPH oxidase genetic deficiency inhibit apoptosis in NGF-deprived sympathetic neurons (Tammariello et al., 2000). Interestingly, unlike circulating polymorphonuclear leukocytes (PMN), PMN in the oral cavity (OPMN) spontaneously generate superoxide radical and $\mathrm{NO}$ in the absence of any stimuli, which results in apoptosis. However, herbimycin A, a protein tyrosine kinase inhibitor, suppressed the activation of caspase- 3 and apoptosis of OPMN (Sato et al., 2002). On the other hand, LPS, TNF- $\alpha$ and the other cytokines induce apoptosis through the production of NO (Albina et al., 1993; Sarih et al., 1993; Tartaglia et al., 1993; Xaus et al., 2000). Interestingly, $\mathrm{H}_{2} \mathrm{O}_{2}$ at low concentration can induce survival pathway of cells, while that at high concentration induce cell apoptosis through activation of SAPK/JNK and caspase-3. This suggests that survival and apoptotic signal pathways through ROS can be competitively regulated (Um, 2001).

\section{Apoptosis induced by activation of $F c R$ and $C R$}

Earlier studies showed that phagocytotic apoptosis was induced through $\mathrm{CR}$ and $\mathrm{FcR}$ ligation (Coxon et al., 1996; Gamberale et al., 1998) and Rho GTPases regulates the phagocytosis mediated through $\mathrm{FcR}$ and CR3 (Caron and Hall, 1998; Massol et al., 1998), which may be implicated to the superoxide formation. Using oligonucleotide microarrays and FACS analysis, it was confirmed that apoptosis can be induced during phagocytosis (Kobayashi et al., 2002).

Although these studies strongly suggest that CRand FcR-ligation with ligands induce apoptosis in neutrophils, it was not clear on the downstream processes resulting in apoptosis of macrophages. Recently, it was shown that $\mathrm{SOZ}$ or IgG-opsonized zymosan (IOZ) induced the apoptosis of macrophages. In contrast to LPS/interferon- $\gamma$ (IFN $\gamma$ )-induced apoptosis, SOZand IOZ-induced apoptosis were strictly dependent on the ROS, which were generated during phagocytosis in the macrophage. In addition, the phagocytosis of macrophages resulted in the release of cytochrome $c$ as well as the activation of caspase- 3 in a superoxide- dependent manner (Kim et al., 2003). Recent study showed that CR3 mediated phagocytosis promotes apoptosis through a caspase $8 / 3$ dependent pathway that is modulated by NADPH-oxidase generated ROS and MAPK/ERK. Moreover, TNF and granulocytemacrophage colony-stimulating factor (GM-CSF), likely to be encountered by phagocytosing neutrophils at inflammatory sites, exploit pro-ROS and anti-ERK apoptotic signals triggered by phagocytosis to promote or suppress phagocytosis-induced cell death respectively, and thus modulate the fate of phagocytosing neutrophils (Zhang et al., 2003).

Activation of caspases induces apoptotic cell death. Many structural and regulatory proteins are inactivated by caspases, while other substrates can be activated. For instance, small GTPases and related proteins including Cdc42, Rabaptin-5, Rac, Ran-GAP, RasGAP, TIAM, Vav-1, and D4-GDI are cleaved by caspases (Kwon et al., 2002; Fischer et al., 2003).

On the other hand, overexpression of SHIP in macrophages leads to an inhibition of phagocytosis mediated by FcyR and CR3 (Cox et al., 2001). However, the activation of SHIP by NADPH oxidase-stimulated Lyn leads to enhanced apoptosis in neutrophils (Gardai et al., 2002).

ROS-induced apoptosis has been studied mostly by using drugs (Bagchi et al., 2001; Boggs et al., 2001; Shen et al., 2001) which are capable of generating intracellular ROS or $\mathrm{H}_{2} \mathrm{O}_{2}$, with respect to cytochrome $c$ release and caspase activation. ROS has been shown directly or indirectly to target mitochondria and release cytochrome $c$ from those organelles into the cytosol (Herrera et al., 2001). It is generally assumed that such release is required for activation of caspase-3. As yet, it is not clear whether the superoxide species generated by NADPH oxidase during phagocytosis, exogenous chemicals, or mitochondrial electron transport during respiration (Raha and Robinson, 2001) have the same mechanism to induce apoptosis of cells.

It was also observed that $\mathrm{p} 21^{\text {WAF1 }}$ was induced, when macrophages were treated with SOZ particles (Kim et al., 2003). In early stage of the induction of apoptosis, p21 $21^{\text {WAF1 }}$ may be increased to protect cells from apoptosis, since p2 $1^{\text {WAF1 }}$ was known to have antiapoptotic and cell cycle arrest functions (Seoane et al., 2002). but p21 $21^{\text {WAF1 }}$ is cleaved by caspase 3 at the onset of apoptosis, losing its apoptosis-suppressing activity (Zhang et al., 1999). Induction of p21 WAF1 in SOZ-treated macrophages is still need to be clarified for its role in apoptosis.

Conclusively, phagocytosis of $\mathrm{SOZ}$ and $\mathrm{IOZ}$ induces superoxide formation, and excessive superoxide causes the cells to die. Rho GTPases play important roles in specific steps. 


\section{Acknowledgement}

This study was supported by Korea Research Foundation Grant (KRF-2000-015-FP0012), the Korea Science and Engineering through the Silver Biotechnology Research Center at Hallym University, and a grant of Korea Health 21 R\&D Project, Ministry of Health \& Welfare, Republic of Korea (02-PJ10-PG6AG01-003).

\section{References}

Aderem A, Underhill DM. Mechanism of phagocytosis in macrophages. Annu Rev Immunol 1999;17:593-623

Albert ML, Kim JI, Birge RB. Alphavbeta5 integrin recruits the Crkll-Dock180-rac1 complex for phagocytosis of apoptotic cells. Nat Cell Biol 2000;2:899-905

Albina JE, Cui S, Mateo RB, Reichner JS. Nitric oxidemediated apoptosis in murine peritoneal macrophages. J Immunol 1993;150:5080-85

Allen LH, Aderem A. Molecular definition of distinct cytoskeletal structures involved in complement- and Fc receptormediated phagocytosis in macrophages. J Exp Med 1996; 184:627-37

Aramaki Y, Takano S, Tsuchiya S. Cationic liposomes induce macrophage apoptosis through mitochondrial pathway. Arch Biochem Biophys 2001;392:245-50

Babior B. NADPH oxidase: An update. Blood 1999;93:146476

Bagchi D, Bagchi M, Stohs SJ. Chromium (VI)-induced oxidative stress, apoptotic cell death and modulation of p53 tumor suppressor gene. Mol Cell Biochem 2001;222:149-58

Bajno L, Peng XR, Schreiber AD, Moore HP, Trimble WS, Grinstein S. Focal exocytosis of VAMP3-containing vesicles at sites of phagosome formation. J Cell Biol 2000;149: 697-706

Boggs SE, McCormick TS, Lapetina EG. Glutathione levels determine apoptosis in macrophages. Biochem Biophys Res Commun 1998;247:229-33

Bokoch GM, Quilliam LA, Bohl BP, Jesaitis AJ, Quinn MT. Inhibition of Rap1A binding to cytochrome b558 of NADPH oxidase by phosphorylation of Rap1A. Science 1991;254: 1794-6

Bokoch GM. Regulation of the human neutrophil NADPH oxidase by the Rac GTP-binding proteins. Curr Opi Cell Biol 1994;6:212-8

Brown EJ. Phagocytosis. BioEssay 1995;17:109-17

Brown GD, Taylor PR, Reid DM, Willment JA, Williams DL, Martinez-Pomares L, Wong SY, Gordon S. Dectin-1 is a major beta-glucan receptor on macrophages. J Exp Med 2002;196:407-12

Caron E, Hall A. Identification of two distinct mechanisms of phagocytosis controlled by different Rho GTPases. Science 1998;282:1717-21
Caron E, Self AJ, Hall A. The GTPase Rap1 controls functional activation of macrophage integrin $\alpha \mathrm{M} \beta 2$ by LPS and other inflammatory mediators. Curr Biol 2000;10:974-8

Chimini G, Chavrier P. Function of Rho family proteins in actin dynamics during phagocytosis and engulfment. Nature Cell Biol 2000;2:E191-6

Chuang TH, Bohi BP, Bokoch GM. Biologocally active lipids are regulators of Rac. GDI complexation. J Biol Chem 1993; 268:26206-11

Chvrier $P$. May the force be with you: Myosin- $X$ in phagocytosis. Nature Cell Biol 2002;4:E169-7

Coppolino MG, Krause M, Hagendorff $P$, Monner DA, Trimble W, Grinstein S, Wehland J, Sechi AS. Evidence for a molecular complex consisting of Fyb/SLAP, SLP-76, Nck, VASP and WASP that links the actin cytoskeleton to Fc $\gamma$ receptor signalling during phagocytosis. J Cell Sci 2001;114: 4307-18

Cox D, Chang P, Zhang Q, Reddy PG, Bokoch GM. Greenberg, S. Requirements of both Rac1 and cdc42 in membrane ruffling and phagocytosis in leukocytes. J Exp Med 1997; 186:1487-94

Cox D, Tseng CC, Bjekic G, Greenberg S. A requirement for phosphatidylinositol 3-kinase in pseudopod extension. J Biol Chem 1999;274:1240-7

Cox D, Dale BM, Kashiwada M, Helgason CD, Greenberg $\mathrm{S}$. A regulatory role for $\mathrm{Src}$ homology 2 domain-containing inositol 5'-phosphatase (SHIP) in phagocytosis mediated by Fc gamma receptors and complement receptor 3 (alpha (M)beta(2); CD11b/CD18). J Exp Med 2001;193:61-71

Cox D, Berg JS, Cammer M, Chinegwundoh JO, Dale BM, Cheney RE, Greenberg S. Myosin $X$ is a downstream effector of $\mathrm{PI}(3) \mathrm{K}$ during phagocytosis. Nature Cell Biol 2002;4: 469-77

Coxon A, Rieu P, Barkalow FJ, Askari S, Sharpe AH, von Andrian UH, Arnaout MA, Mayadas TN. A novel role for the beta 2 integrin CD11b/CD18 in neutrophil apoptosis: a homeostatic mechanism in inflammation. Immunity 1996;5:653-6

Crespo $P$, Schuebel KE, Ostrom AA, Gutkind JS, Bustelo $X R$. Phosphotyrosine-dependent activation of Rac-1 GDP/ GTP exchange by the vav proto-oncogene product. Nature 1997;385:169-72

Dewas C, Fay M, Gougerot-Pocidalo M, El-Benna J. The mitogen-activated protein kinase extracellular signal-regulated kinase $1 / 2$ pathway is involved in formyl-methionyl-leucyl-phenylalanine-induced p47PHOX phosphorylation in human neutrophils. J Immunol 2000;165:5238-44

Diakonova M, Bokoch G, Swanson JA. Dynamics of cytoskeletal proteins during Fcgamma receptor-mediated phagocytosis in macrophages. Mol Biol Cell 2002;13:402-11

Fadok VA, Bratton DL, Rose DM, Pearson A, Ezekewitz RA, Henson PM. A receptor for phosphatidylserine-specific clearance of apoptotic cells. Nature 2000;405:85-90

Fischer U, Jnicke RU, Schulze-Osthoff K. Many cuts to ruin: a comprehensive update of caspase substrates. Cell Death Differ 2003;10:76-100

Gamberale R, Giordano M, Trevani AS, Andonegui G, 
Geffner JR. Modulation of human neutrophil apoptosis by immune complexes. J Immunol 1998;161:3666-74

Gardai S, Whitlock BB, Helgason C, Ambruso D, Fadok V, Bratton D, Henson PM. Activation of SHIP by NADPH oxidase-stimulated Lyn leads to enhanced apoptosis in neutrophils. J Biol Chem 2002;277:5236-46

Giaimis J, Lombard Y, Fonteneau P, Muller CD, Levy R, Makaya-Kumba M, Lazdins J, Poindron P. Both mannose and beta glucan receptors are involved in phagocytosis of unopsonized, heat-killed Saccharomyces cerevisiae by murine macrophages. J Leuko Biol 1993;54:564-71

Hackam DJ, Rotstein OD, Schreiber A, Zhang W, Grinstein $S$. Rho is required for the initiation of calcium signaling and phagocytosis by Fcy receptors in macrophages. J Exp Med 1997;186:955-66

Hackam DJ, Rotstein OD, Sjolin C, Schreiber AD, Trimble WS, Grinstein S. v-SNARE-dependent secretion is required for phagocytosis. Proc Natl Acad Sci USA 1998;95:11691-6

Hall A. Rho GTPase and the actin cytoskeleton. Science 1998;279:509-14

Herrera B, Alvarez AM, Sanchez A, Fernandez M, Roncero $C$, Benito M, Fabregat I. Reactive oxygen species mediates the mitochondrial-dependent apoptosis induced by transforming growth factor beta in fetal hepatocytes. FASEB $\mathrm{J}$ 2001;15:741-51

Heyworth PG, Curnutte JT, Nauseef WM, Volpp BD, Pearson DW, Rosen H, Clark RA. Neutrophil nicotinamide adenine dinucleotide phosphate oxidase assembly. Translocation of p47-phox and p67-phox requires interaction between p47-phox and cytochrome b558. J clin Invest 1991;87:352-6

Heyworth PG, Erickson RW, Ding J, Curnutte JT, Badwey JA. Naphthalenesulfonamides block neutrophil superoxide production by intact cells and in a cell-free system: is myosine light chain kinase responsible for these effects? Biochem J 1995;311:81-7

Huang YC, Soukup J, Harder S, Becker S. Mitochondrial oxidant production by a pollutant dust and NO-mediated apoptosis in human alveolar macrophage. Am J Physiol Cell Physiol 2003;284:C24-32

Kasahara Y, Iwai K, Yachie A, Ohta K, Konno A, Seki H, Miyawaki $\mathrm{T}$, Taniguchi $\mathrm{N}$. Involvement of reactive oxygen intermediates in spontaneous and CD95 (Fas/APO-1)-mediated apoptosis of neutrophils. Blood 1997;89:1748-53

Kawano Y, Fukata Y, Oshiro N, Amano M, Nakamura T, Masaaki I, Matsumura F, Inagaki M, Kaibuchi K. Phosphorylation of myosine-binding subunit (MBS) of myosine phosphatase by Rho-kinase in vivo. J Cell Biol 2000;147:1023-37

Kim C, Dinauer MC. Rac2 is an essential regulator of neutrophil nicotinamide adenine dinucleotide phosphate oxidation in response to specific signaling pathways. J Immunol 2001;166:1223-32

Kim JS, Kwon HY, Choi WH, Jeon CY, Kim JI, Kim J, Lee JY, Kim YS, Park JB. Phagocytosis of serum- and IgGopsonized zymosan particles induces apoptosis through superoxide but not nitric oxide in macrophage J774A.1. Exp Mol Med 2003;35:211-21

Kimura K, Ito M, Amano M, Chihara K, Fukata Y, Nakafuka
M, Yamamori B, Feng J, Nakano T, Okawa K, Iwamatsu A, Kaibuchi K. Regulation of myosine phosphatase by Rho and Rho-associated kinase (Rho-kinase). Science 1996;273: 245-8

Kobayashi SD, Voyich JM, Buhl CL, Stahl RM, DeLeo FR. Global changes in gene expression by human polymorphonuclear leukocytes during receptor-mediated phagocytosis: cell fate is regulated at the level of gene expression. Proc Natl Acad Sci USA 2002;99:6901-6

Koo HY, Shin I, Lee ZW, Lee SH, Kim SH, Lee CH, Kang $\mathrm{HS}, \mathrm{Ha}$ KS. Roles of RhoA and phospholipase $\mathrm{A} 2$ in the elevation of intracellular $\mathrm{H}_{2} \mathrm{O}_{2}$ by transforming growth factor-b in Swiss 3T3 fibroblast. Cell Signal 1999;11:677-83

Kreck ML, Uhlinger DJ, Tyagi SR, Inge KL, Lambeth JD. Participation of the small molecular weight GTP-binding protein Rac1 in cell-free activation and assembly of the respiratory burst oxidase. Inhibition by a carboxyl-terminal Rac peptide. J Biol Chem 1994;269:4161-8

Kusner JD, Hall CF, Schlesinger LS. Activation of phospholipase $D$ is tightly coupled to the phagocytosis of Mycobacterium tuberculosis or opsonized zymosan by human macroophages. J Exp Med 1996;184:585-95

Kwon KB, Park EK, Ryu DG, Park BH. D4-GDI is cleaved by caspase-3 during daunorubicin-induced apoptosis in HL-60 cells. Exp Mol Med 2002;34:32-7

Le Cabec V, Cols C, Maridonneau-Parini I. Nonopsonic phagocytosis od zymosan and mycobacterium kansasii by CR3 (CD11b/CD18) involves distinct molecular determinants ans is or is not coupled with NADPH oxidase activation. Infec Immunity 2000;68:4736-44

Lee ZW, Kweon SM, Kim SJ, Kim JH, Cheong C, Park YM, $\mathrm{Ha}$ KS. The essential role of $\mathrm{H}_{2} \mathrm{O}_{2}$ in the regulation of intracellular $\mathrm{Ca}^{2+}$ by epidermal growth factor in Rat-2 fibroblasts. Cell Signal 2000;12:91-8

Löfgren $R$, Serrander L, Forsberg $M$, Wisson $\AA$, Wasteson $\AA$ A, Stendahl O. Biochim Biophys Acta 1999;1452:46-59

Machesky LM, Insall RH. Scar1 and the related WiskottAldrich syndrome protein, WASP, regulate the actin cytoskeleton through the Arp2/3 complex. Current Biology 1998; 8:1347-56

Malcolm KC, Ross AH, Qiu RG, Symons M, Exton JH. Activation of rat liver phospholipase $D$ by the small GTPbundung protein RhoA. J Biol Chem 1994;269:25951-4

Mansfield PJ, Shayman JA, Boxer LA. Regulation of polymorphonuclear leukocyte phagocytosis by myosin light chain kinase after activation of mitogen-activated protein kinase. Blood 2000;95:2407-12

Marshall JG, Booth JW, Stambolic V, Mak T, Balla T, Schreiber AD, Meyer T, Grinstein S. Restricted accumulation of phosphatidylinositol 3-kinase products in a plasmalemmal subdomain during Fc gamma receptor-mediated phagocytosis. J Cell Biol 2001;153:1369-80

Massol P, Montocourrier P, Guillemot JC, Chavrier P. FC receptor-mediated phagocytosis requires $\mathrm{Cdc} 42$ and Rac1. EMBO J 1998;17:6219-29

Matsui S, Matsumoto S, Adachi R, Kusui K, Hirayama A, Watanabe $\mathrm{H}$, Ohashi K, Mizuno K, Yamaguchi T, Kasahara 
T, Suzuki K. LIM kinase 1 modulates opsonized zymosantriggered activation of macrophage-like U937 cells. J Biol Chem 2002;277:544-9

May RC, Caron E, Hall A, Machesky LM. Invovement of the Arp2/3 complex in phagocytosis mediated by FcyR or CR3. Nature Cell Biol 2000;2:246-8

May RC, Machesky LM. Phagocytosis and the actin cytoskeleton. J Cell Sci 2001;114:1061-77

Mizuno T, Kaibuchi K, Ando S, Musha T, Hiraoka K, Takaishi $\mathrm{K}$, Asada M, Nunoi $\mathrm{H}$, Matsuda I, Takai $\mathrm{Y}$. Regulation of the superoxide-generating NADPH oxidase by a small GTPbinding protein and its stimulatory and inhibitory GDP/GTP exchange proteins. J Biol Chem 1992;267:10215-8

M'Rabet L, Coffer P, Zwartkruis F, Franke B, Segal AW, Koenderman L, Bos JL. Activation of the small GTPase rap1 in human neutrophils. Blood 1998; 92:2133-40

Nimnual AS, Taylor LJ, Bar-Sagi D. Redox-dependent downregulation of Rho by Rac. Nature Cell Biol 2003;5:236-41

Park JW, Babior BM. Activation of the leukocyte NADPH oxidase subunit p47phox by protein kinase C. A phosphorylation-dependent change in the conformation of the C-terminal end of p47phox. Biochemistry 1997;36:7474-80.

Patel JC, Hall A, Caron E. Vav regulates activation of Rac but not Cdc42 during FcyR-mediated phagocytosis. Mol Biol Cell 2002;13:1215-26

Quinn MT, Parkos CA, Walker L, Orkin SH, Dinauer MC, Jesaitis AJ. Association of a Ras-related protein with cytochrome b of human neutrophils. Nature 1989;342:198200

Raha S, Robinson BH. Mitochondria, oxygen free radicals, and apoptosis. Am J Med Genetics 2001;106: 62-70

Ravetch JV. Fc receptor. Curr Opin Immunol 1997;9:121-5

Regier DS, Greene DG, Sergeant S, Jesaitis AJ, McPhail LC. Phosphorylation of $p 22^{\text {phox }}$ is mediated by phospholipase D-dependnet and -independent mechanisms. J Biol Chem 2000;275:28406-12

Ridley AJ. Rho family proteins: coordinating cell responses. Trends Cell Biol 2001;11:471-7

Ross GD, Cain JA, Lachmann PJ, Membrane complement receptor type 3 (CR3) has lectin-like properties analogous to bovine conglutinin and functions as a receptor for zymosan and rabbit erythrocytes as well as a receptor for iC $3 b$. J Immunol 1985;134:3307-14

Ross GD. Regulation of the adhesion versus cytotoxic functions of the Mac-1/CR3/alphaMbeta2-integrin glycoprotein. Crit Rev Immunol 2000;20:197-222

Rotrosen D, Yeung CL, Katkin JP. Production of recombinant cytochrome b558 allows reconstitution of the phagocyte NADPH oxidase solely from recombinant proteins. J Biol Chem 1993;268:14256-60

Salh B, Assi K, Huang S, O'Brien L, Steinbrecher U, Gomez-Munoz A. Dissociated ROS production and ceramide generation in sulfasalazine-induced cell death in Raw 264.7 cells. J Leukoc Biol 2002;72:790-9

Sanders LC, Matsumura F, Bokoch GM, de Lanerolle P.
Inhibition of myosin light chain kinase by p21-activated kinase. Science 1999;283:2083-5.

Sarih M, Souvannavong V, Adam A. Nitric oxide synthase induces macrophage death by apoptosis. Biochem Biophys Res Commun 1993;191:503-8

Sato EF, Higashino M, Ikeda K, Wake R, Matsuo M, Utsumi $\mathrm{K}$, Inoue M. Oxidative stress-induced cell death of human oral neutrophils. Am J Physiol Cell Physiol 2002;284:C104853

Seoane J, Le HV, Massague J. Myc suppression of the p21(Cip1) Cdk inhibitor influences the outcome of the p53 response to DNA damage. Nature 2002;419:729-34

Serrander L, Larsson J, Lundquist $H$, Lindmark M, Fallman M, Dahgren C, Stendahl O. Particles binding b2-integrins mediate intracellular production of oxidative metabolites in human neutrophils independently of phagocytosis. Biochi Biophys Acta 1999;1452:133-44

Shen HM, Zhang Z, Zhang QF, Ong CN. Reactive oxygen species and caspase activation mediate silica-induced apoptosis in alveolar macrophages. Am J Physiol Lung Cell Mol Physiol 2001;280:L10-7

Suen YK, Fung KP, Lee CY, Kong SK. Gliotoxin induces apoptosis in cultured macrophages via production of reactive oxygen species and cytochrome c release without mitochondrial depolarization. Free Radic Res 2001;35:1-10

Taborda CP, Casadevall A. CR3 (CD11b/CD18) and CR4 (CD11c/CD18) are involved in complement-independent antibody-mediated phagocytosis of Cryptococcus neoformans. Immnity 2002;16:791-802

Tammariello SP, Quinn MT, Estus S. NADPH oxidase contributes directly to oxidative stress and apoptosis in nerve growth factor-deprived sympathetic neurons. J Neurosci 2000; $20:$ RC53:1-5

Tartaglia LA, Rothe M, Hu YF, Goeddel DV. Tumor necrosis factor's cytotoxic activity is signaled by the p55 TNF receptor. Cell 1993;73:213-6

Totsukawa G, Yamakita Y, Yamashiro S, Hartshorne DJ, Sasaki Y, Matsumura F. Distinct roles of ROCK (Rho-kinase) and MLCK in spatial regulation of MLC phosphorylation for assembly of stress fibers and focal adhesions in $3 \mathrm{~T} 3 \mathrm{fi}-$ broblasts. J Cell Biol 2000;150:797-806

Um HD. Cell death and survival pathways induced by oxidative stress, and their interactions. Exp Mol Med 2001; 33:Suppl 111-116

Wientjes FB, Panayotou G, Reeves E, Segal AW. Interactions between cytosolic components of the NADPH oxidase: p40phox interacts with both p67phox and p47phox. Biochem J 1996; 317:919-24

Xaus J, Comalada M, Valledor AF, Lloberas J, LopezSoriano F, Argiles JM, Bogdan C, Celada A. LPS induces apoptosis in macrophages mostly through the autocrine production of TNF-alpha. Blood 2000;95:3823-31

Yamada T, Goto M, Punj V, Zaborina O, Kimbara K, Das Gupta TK, Chakrabarty AM. The bacterial redox protein azurin induces apoptosis in $\mathrm{J} 774$ macrophages through complex formation and stabilization of the tumor suppressor 
protein p53. Infect Immun 2002;70:7054-62

Yamamori T, Inanami O, Nagahata $H$, Cui YD, Kuwabara M. Roles of p38 MAPK, PKC and PI3-K in the signaling pathways of NADPH oxidase activation and phagocytosis in bovine polymorphonuclear leukocytes. FEBS Lett 2000;467: 253-8

Yamamori T, Inanami $\mathrm{O}$, Sumimoto $\mathrm{H}$, Akasaki T, Nagahata $H$, Kuwabara M. Relationship between p38 mitogen-activated protein kinase and small GTPase Rac for the activation of NADPH oxidase in bovine neutrophils. Biochem Biophys Res Comm 2002;93:1571-8
Zhang B, Hirahashi J, Cullere X, Mayadas TN. Elucidation of molecular events leading to neutrophil apoptosis following phagocytosis: Cross-talk between caspase 8 , reactive oxygen species and MAPK/ERK activation. J Biol Chem 2003;278: 28443-54

Zhang Q, Cox D, Tseng CC, Donaldson JG, Greenberg S. A requirement for ARF6 in Fcgamma receptor-mediated phagocytosis in macrophages. J Biol Chem 1998;273:19977-81

Zhang Y, Fujita N, Tsuruo T. Caspase-mediated cleavage of p21 $1^{\text {WAF } 1 / \text { Cip1 }}$ converts cancer cell from growth arrest to undergoing apoptosis. Oncogene 1999;18:1131-8 